\title{
At-Home Activities and Subjective Well-Being of Foreign College Students in Thailand during the COVID-19 Pandemic Outbreak
}

\author{
Monorom RITH* and Mongkut PIANTANAKULCHAI \\ School of Civil Engineering and Technology, Sirindhorn International Institute of Technology, \\ Thammasat University, Pathum Thani 12120, Thailand
}

('Corresponding author's e-mail: rith_monorom@dlsu.edu.ph)

Received: 21 April 2020, Revised: 29 June 2020, Accepted: 21 July 2020

\begin{abstract}
Sirindhorn International Institute of Technology (SIIT) is an international institute of Thammasat University (TU), located in Pathum Thani, Thailand. The courses are offered in English, and many foreign students are studying at SIIT-TU. The classes have been suspended since 16 March 2020 to slow down the COVID-19 disease spread, and the students are suggested to study online at home. The present study intends to understand the at-home activities and well-being of foreign students. A web-based survey was conducted from 22 through 23 March 2020 to record the activities and well-being of the students on 20 and 21 March 2020. Happiness and stress levels with the seven-points Likert scales were considered as the two output variables $(1=$ lowest and $7=$ highest $)$. The ordered probit model was applied to develop the subjective well-being models, taking into account at-home activities. The results highlighted that students who were happier were more likely to study for longer at home, but that studying for longer increases stress levels. Students who were less happy and more stressed were more likely to speak on the phone for longer, while doing exercise at home for longer increased the likelihood of happiness. This paper contributes to a better understanding of at-home activities associated with well-being of foreign students in Thailand during the COVID-19 outbreak.
\end{abstract}

Keywords: COVID-19, Well-being, Ordered probit model, At-home activities, Thailand

\section{Introduction}

In January 2020, the World Health Organization (WHO) declared the COVID-19 pandemic outbreak to be a public health emergency and the world's main concern [1]. The WHO reported 1,279,722 confirmed cases and 72,616 confirmed deaths on 7 April 2020 across 211 countries and territories [2]. There is no vaccine against the COVID-19 disease, and more than 11 vaccine candidates are in development [3]. The meteorological condition of low temperature, mild diurnal temperature range, and low humidity are likely the driving factors of the virus transmission [4]. Most of the governments in the world have decided to temporarily stop the operation of public transport modes and flights, close shopping malls and restaurants (except for online food delivery services), and suspend classes to fight against the COVID-19 disease spread. These activities collapse the national and global economies and degrade the quality of social welfare. Isolation, quarantine, and social distancing are good solutions to slow down and curb the COVID-19 disease infection in communities [5]. This approach has abruptly changed daily lives. Many people are more likely to stay at home and rarely go out unless they have an indispensable task to do because of fear of getting infected with the COVID-19 disease. Some countries have declared a state of emergency during this turbulent time. Correspondingly, people lose some part of their freedom to do out-of-home activities and stay at home for longer than usual. People, in turn, experience less happiness and higher stress. The COVID-19 pandemic has provoked a simultaneous epidemic of fear, anxiety, and depression [6]. The WHO also reports that the COVID-19 pandemic is 
causing widespread concern, fear, and stress, and how we combat against and react to the stressful situation unfolding very uncertainly in our lives and communities is important [7]. Also, the WHO considers the effect of COVID-19 on the mental health and psychological well-being of humans to be a very important topic [8]. There are many different target groups vulnerable to the COVID-19 disease, such as, healthcare workers and professionals, older adults, carers of children, low-income people, people with chronic disease, and migrants and refugees. Among these target groups, healthcare workers and professionals are exposed to the COVID-19 disease most, because they work with COVID-19 infected patients. Healthcare providers are particularly vulnerable to distress and anxiety disorders [9]. Shanafelt et al. [10] explored the tangible sources of anxiety among healthcare professionals during the pandemic, because a sound understanding of driving factors of anxiety can allow healthcare leaders to address concerns and provide specific supports to their healthcare workforce. The findings highlighted that healthcare professionals need their organization to assure that they and their families will be supported, both medically and socially, if they become infected with the COVID-19 disease. McLaren et al. [11] corroborated that women will experience a worsening of their burdens unless the pandemic is well under control because the majority of frontline healthcare workers are women. Furthermore, strategic political responses include women in the development of disaster responses and the control of resources [11]. Furthermore, there are many challenges in the infection projection arena, specifically a limited supply of personal protective equipment and respiratory isolation rooms [3]. This implies that women are more vulnerable than men to the COVID-19 disease pandemic. Corburn et al. [12] intended to provide practice and policy suggestions to arrest the COVID-19 disease spread, improve medical care, and enhance the well-being of the urban poor located in illegal settlements. However, a study of subjective well-being among a migrant group has not been conducted during the ripple effect, specifically foreign college students in Thailand.

Thailand has the fifth most confirmed COVID-19 cases in southeast Asia, after Singapore, Malaysia, the Philippines, and Indonesia [2]. The government declared a state of emergency, being implemented from 26 March to 30 April, to slow down the COVID-19 disease spread [13]. To be selfquarantined, senior citizens, children under the age of five, and people vulnerable to health conditions were asked not to leave their homes unless they had necessary tasks to do. All borders were temporarily closed, and travel into Thailand via air, land, and sea was denied. The order also banned large gatherings, and venues with high risks of infection were closed as well. Classes were suspended, and makeup classes for college students were carried out online. College students experienced at-home activities for longer than usual, and many foreign college students were still in Thailand. Immobility reduces physical activities and may cause decline in physical health and general well-being [14]. Thai students can get mental and emotional support from their families because they can return to and live with them. Unlike Thai students, foreign students live in studios and dormitories in Thailand. We wondered about their wellbeing and their at-home activities. The WHO also mentions that the role we can play is to seek the social and emotional support of others [8]. The WHO also suggests people engage in physical activities during the COVID-19 outbreak to take care of themselves [1]. Healthcare workers also suggest people manage their mental health and psychological well-being during the pandemic, because it is important to manage physical health [1]. The primary motivation of this research is to improve happiness and heal stress of foreign students in Thailand during the ripple effect. Foreign students are a migrant group. Migrant groups are vulnerable to mental health disorders, ravaged by the COVID-19 disease outbreak.

This study intended to explore at-home activities associated with the well-being of foreign students in Thailand, through a case study of Sirindhorn International Institute of Technology (SIIT). SIIT is an international institute of Thammasat University (TU), located in Pathum Thani, Thailand. The courses are offered in English as the medium of instruction, and many foreign students are studying at SIIT-TU. To the best of authors' knowledge, this is the first study of the well-being and at-home activity involvement of foreign students in Thailand during the class suspension caused by the COVID-19 pandemic outbreak. The study used a primary data set of 42 samples, collected on 22 and 23 March 2020 using the web-based survey approach, and the ordered probit model was applied to model the dataset. Two output variables of social welfare were chosen in our study: happiness and stress. This could be explained as, according to the preliminary evidence, symptoms of anxiety and depression (16 - $28 \%)$ and self-reported stress $(8 \%)$ 
are typical psychological reactions to the COVID-19 transmission [15]. Happiness is the most used indicator of social welfare in research. The novelty of the present study is two-fold: a new case study and new factors of at-home activities. The importance of this research is that the findings are highly expected to be informative for improvement of the life satisfaction and mental health resilience of foreign students in Thailand during the ripple effect. Furthermore, universities can provide foreign students with the ability to address specific concerns.

\section{Materials and methods}

In the following subsections, we briefly describe the study design and setting, ethical approval, data collection, descriptive analysis, and the ordered regression model.

\section{Study design and setting}

The questionnaire form was made up of three main sections, i.e., socioeconomic characteristics, athome activities, and subjective well-being. Subjective well-being is a self-reporting measure that is used to describe how people experience the quality of their lives. In the context of the COVID-19 outbreak, we intended to understand the happiness and stress of foreign college students because they are required to study online at dwellings, with no mass gatherings. The WHO and public health authorities around the world stated that the COVID-19 pandemic is generating stress and degrading social welfare throughout the population globally [1]. Therefore, stress and happiness with the seven-points Likert scales from 1 (the lowest) to 7 (the highest) were used as the indicators of subjective well-being.

Sirindhorn International Institute of Technology (SIIT), an international institute of Thammasat University (TU), located in Pathum Thani, was selected as the case study because this institute uses English as the medium of instruction for foreign and Thai students. Only foreign students living in the dormitory of SIIT International Residence Hall, located in Ban Kadi, Pathum Thani, were suggested to fill out the questionnaire form via Google Form. A map of the dormitory is illustrated in Figure 1.
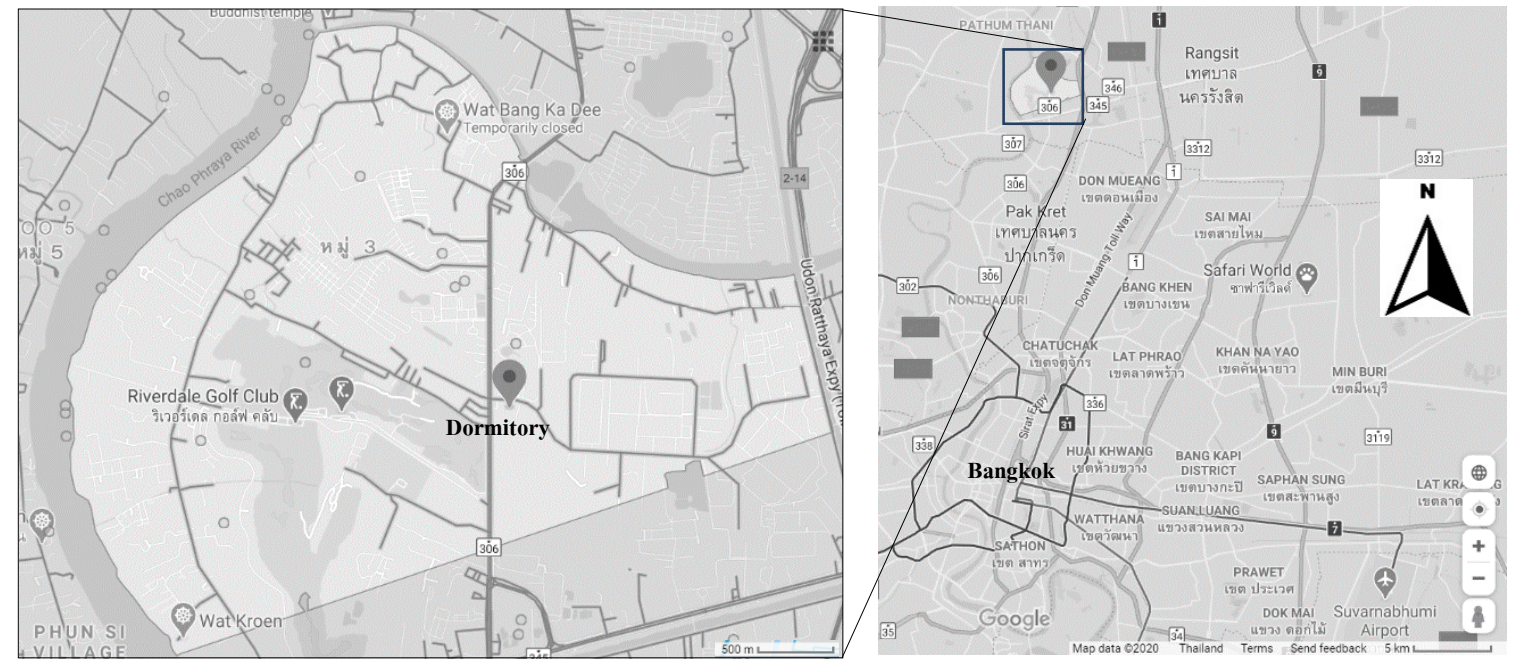

Figure 1 The map of SIIT International Residence Hall for foreign college students. 


\section{Ethical approval}

The authors obtained consent from a coordinator of the dormitory to post the Google Form link on the Facebook page of the dormitory. Also, the header of the questionnaire form showed the information, "The survey is being conducted by the Transportation Research Laboratory, School of Civil Engineering and Technology, SIIT-TU. This study intends to explore, understand, and model activity involvement and social welfare of SIIT students during the COVID-19 outbreak. Your answers are treated with the utmost confidentiality."

\section{Data collection}

The web-based survey approach was applied to collect data online, and the Google Form was posted on the Facebook group of SIIT-TU students at the Bang Kadi dormitory, Pathum Thani, on 22 and 23 March 2020. There were only 42 foreign students who volunteered to fill out the form, and all the information of each data sample was complete, because the authors used the feature "Required" for all the questions of the survey form. The respondents, therefore, could not skip any questions, and there were 42 observations for data modeling and no exclusive observation. The number of foreign students living in the dormitory was less than 200 . The sample size, therefore, provides a confidence level of $90 \%$, with a margin of error of $11.31 \%$, if the sample estimate of proportion in the population is assumed to be 0.5 [16]. The survey form suggested the students report their at-home activities and subjective well-being on 20 and 21 March 2020 and answer the questions of socioeconomic characteristics. 20 March was a Friday, and 21 March was a Saturday. These two days were used as being the representatives of the working day and weekend. For the socioeconomic characteristics, we requested the respondents to fill out the form related to gender (i.e., male or female), educational level (i.e., undergraduate or graduate student), and monthly allowance (i.e., less than 10,000 Baht or 10,000 Baht and more). For at-home activities, we suggested the respondents report the duration of each at-home activity, including study at home, watch movies/listen to music, play computer/smartphone games, spend time using social media, speak on the phone, do exercise at home, or read the news related to the COVID-19 disease.

\section{Descriptive analysis}

The descriptive statistics of the data sample are presented in Table 1. The table highlighted that the average happiness and stress scales were 4.05 and 4.43, respectively. This implies that students were typically a little bit more stressed than happy. The students spent the least amount of time doing exercise at home, as compared to the other at-home activities. The average duration of each at-home activity was very close to the minimum value compared to the maximum value. Therefore, the distribution curve of each at-home activity was left-skewed. For the socioeconomic variables, we used a dummy code to rearrange the categorical variables, because dummy coding allows for non-linear effects in the levels of attributes and is easy for the interpretation of model estimation results [17].

The Pearson Product-Moment Correlation method was applied to identify the strength of relations among the at-home activities and individual characteristics and control the multicollinearity problem. The strength of the relation between the observed variables is listed in Table 2. It highlighted that gender had a negative moderate correlation with the speaking-on-phone variable. Watching movies/listening to music had a moderate positive association with playing computer/phone games and using social media. This implies that males were less likely to speak on the phone than females, and those who were likely to watch movies/listen to music were more likely to play computer/phone games and spend time online using social media. The happiness and stress variables had a moderate negative correlation, which indicates that those who were happier were less stressed, and vice versa. 
Table 1 Descriptive statistics of the sample data.

\begin{tabular}{|c|c|c|c|c|c|}
\hline Variables & Description & Mean & SD & Min & Max \\
\hline \multicolumn{6}{|c|}{ Individual characteristics } \\
\hline Gender & $1=$ male $; 0=$ female & 0.71 & 0.45 & 0.00 & 1.00 \\
\hline Education & $1=$ master $/ \mathrm{PhD}$ student $0=$ bachelor student & 0.69 & 0.47 & 0.00 & 1.00 \\
\hline Allowance & $\begin{array}{l}1=\geq 10,000 \text { Baht } / \text { month } ; 0=<10,000 \\
\text { Baht } / \text { month }\end{array}$ & 0.67 & 0.47 & 0.00 & 1.00 \\
\hline \multicolumn{6}{|c|}{ At-home activities } \\
\hline Study & Duration of study at home (hours) & 6.27 & 4.11 & 0.00 & 16.00 \\
\hline Movies & $\begin{array}{l}\text { Duration of watching movies/listing to music } \\
\text { (hours) }\end{array}$ & 2.98 & 2.66 & 0.00 & 15.00 \\
\hline Games & $\begin{array}{l}\text { Duration of playing computer/phone games } \\
\text { (hours) }\end{array}$ & 2.42 & 3.26 & 0.00 & 15.00 \\
\hline Social media & Duration of using social media (hours) & 2.80 & 3.06 & 0.40 & 15.00 \\
\hline Phone & Duration of speaking on phone (hours) & 0.79 & 0.66 & 0.00 & 3.00 \\
\hline Exercise & Duration of doing exercise at home (hours) & 0.36 & 0.41 & 0.00 & 2.00 \\
\hline COVID-19 & $\begin{array}{l}\text { Duration of reading the news about COVID- } \\
19 \text { (hours) }\end{array}$ & 0.94 & 1.48 & 0.08 & 11.67 \\
\hline \multicolumn{6}{|l|}{ Well-being } \\
\hline Happiness & $\begin{array}{l}\text { Seven-point Likert scale from } 1 \text { (low) to } 7 \\
\text { (high) }\end{array}$ & 4.05 & 1.42 & 1.00 & 7.00 \\
\hline Stress & $\begin{array}{l}\text { Seven-point Likert scale from } 1 \text { (low) to } 7 \\
\text { (high) }\end{array}$ & 4.43 & 1.73 & 1.00 & 7.00 \\
\hline
\end{tabular}

Table 2 Correlation coefficients of variables.

\begin{tabular}{|c|c|c|c|c|c|c|c|c|c|c|c|c|}
\hline & Gender & Education & Allowance & Study & Movie & Game & Social media & Phone & Exercise & Covid-19 & Happiness & Stress \\
\hline Gender & \begin{tabular}{|l|l|}
1.000 \\
\end{tabular} & & & & & & & & & & & \\
\hline Education & 0.033 & 1.000 & & & & & & & & & & \\
\hline Allowance & 0.112 & 0.401 & 1.000 & & & & & & & & & \\
\hline Study & 0.191 & 0.139 & -0.101 & 1.000 & & & & & & & & \\
\hline Movie & 0.029 & -0.196 & -0.078 & 0.199 & 1.000 & & & & & & & \\
\hline Game & 0.205 & -0.223 & -0.278 & 0.293 & 0.575 & 1.000 & & & & & & \\
\hline Social media & -0.069 & -0.045 & ] -0.101 & 0.189 & 0.471 & 0.367 & 1.000 & & & & & \\
\hline Phone & -0.448 & 0.163 & 0.232 & -0.099 & -0.025 & -0.216 & 0.151 & 1.000 & & & & \\
\hline Exercise & -0.147 & 0.124 & 0.136 & -0.062 & -0.069 & 0.000 & -0.153 & 0.065 & 1.000 & & & \\
\hline Covid-19 & 0.007 & 0.146 & 0.161 & -0.044 & [1] -0.103 & -0.138 & 0.199 & 0.127 & 0.039 & 1.000 & & \\
\hline Happiness & -0.072 & [ -0.087 & 0.024 & 0.033 & 0.104 & -0.114 & -0.155 & -0.301 & 0.134 & -0.247 & 1.000 & \\
\hline Stress & -0.057 & -0.267 & -0.029 & -0.196 & -0.084 & 0.023 & \begin{tabular}{|l|l}
0.020 \\
\end{tabular} & 0.300 & 0.131 & 0.165 & -0.547 & 1.000 \\
\hline
\end{tabular}

Ordered probit model

The Likert-scales of happiness and stress from 1 to 7 (i.e., 1 is the lowest, and 7 is the highest) were the ordinal output variables. In this regard, the ordered regression model was suitable for data modeling. In our study, the ordered probit model was applied to understand the at-home activities associated with happiness and stress levels. We assumed that individual characteristics and at-home activities were associated with happiness and stress. A latent continuous output variable, $y^{*}$, can be written as a function of independent variables [18], as expressed in Eq. (1): 
where $\beta$ and $x$ are column vectors of coefficients and independent variables, respectively. $e$ is the error term. The latent continuous output variable can be linked to the observed ordinal output variable, $y$, as expressed as Eq. (2) [18]:

$y \leq m$ if $y^{*}<\tau_{m}(1 \leq m \leq M)$

where $m$ is an outcome category $(1 \leq m \leq M ; M=7) . \tau_{m}$ is a cut point on the latent continuous scale. For a category $m$, the respective lower and upper bounds of the interval are $\tau_{m-1}$ and $\tau_{m}$. The observed category, $y$, can be expressed as Eq. (3) [18]:

$y=m$ if $\tau_{m-1} \leq y^{*}<\tau_{m} ; \quad(1 \leq m \leq M)$

where $y$ is an ordinal output variable (i.e., happiness and stress). A probability of a category, $m$, can be written as the equation below [18]:

$\operatorname{Pr}(y=m \mid x)=\operatorname{Pr}(y \leq m \mid x)-\operatorname{Pr}(y<m-1 \mid x)$

or

$\operatorname{Pr}(y=m \mid x)=F\left(\tau_{m}-\beta^{\prime} x\right)-F\left(\tau_{m-1}-\beta^{\prime} x\right)$

$F$ is the cumulative distribution function (CDF). We assume that $\tau_{0}=-\infty$ and $\tau_{M}=+\infty[18]$. There are only six cut point estimates. The detail of the ordered probit model is presented in [18]. The package "oglmx" of R program was used to estimate the models [19], using a Core i3 laptop with a 4 GB RAM.

\section{Results and discussion}

The estimation results of the streamlined models of happiness and stress levels are shown in Table 3. The gender and movie variables were deliberately removed to control the multicollinearity problem for model development because the gender variable had a moderate negative association with the speakingon-phone variable, while the movie variable was positively correlated with the game and social media variables at a moderate strength (Table 2). These developed models allow us to understand how at-home activities and individual characteristics are associated with well-being. A positive coefficient implies a relationship between input and output variables that change together, while a negative coefficient describes an inverse relationship between input and output variables. The coefficient estimates imply that master/Ph.D. students were less happy and stressed than bachelor students (but the coefficient is significant at the 0.05 level for the happiness level model), while those having a higher allowance were happier and more stressed than those having a lower allowance (but not significant at the 0.05 level). The coefficient of the study variable indicates that students who were happier and less stressed were more likely to study for longer at home, but the impact of the variable is significant at the 0.1 level for the happiness level model, and not significant for the stress level model. Students who were less happy and more stressed were more likely to speak on the phone for longer, while doing exercise at home for longer increased the likelihood of happiness, and those who were more stressed were more likely to do exercise for longer than students who were less stressed. Students who were happier are less likely to read the news of COVID-19 disease. On the other hand, reading the news about the COVID-19 disease is positively correlated with stress. 
Table 3 Model estimation results of subjective well-being - coefficient (standard error).

\begin{tabular}{lcc}
\hline Variables & Happiness level (HL) & Stress level (SL) \\
\hline Education & $-0.332(0.279)$ & $-0.757(0.288)^{* *}$ \\
Allowance & $0.353(0.274)$ & $0.028(0.271)$ \\
Study & $0.057(0.03)$ & $-0.02(0.03)$ \\
Games & $-0.038(0.041)$ & $0.049(0.041)$ \\
Social media & $0.015(0.044)$ & $-0.031(0.043)$ \\
Phone & $-0.35(0.184)$. & $0.71(0.198)^{* * *}$ \\
Exercise & $0.707(0.284)^{*}$ & $0.474(0.313)$ \\
Covid_19 & $-0.032(0.073)$ & $0.18(0.092)$. \\
Cut points & & $-1.575(0.384)^{* * *}$ \\
$\tau_{1}$ & $-1.172(0.336)^{* * *}$ & $-1.46(0.375)^{* * *}$ \\
$\tau_{2}$ & $-1.103(0.331)^{* * *}$ & $-0.667(0.347)$. \\
$\tau_{3}$ & $-0.924(0.322)^{* *}$ & $-0.31(0.341)$ \\
$\tau_{4}$ & $-0.287(0.305)$ & $0.231(0.333)$ \\
$\tau_{5}$ & $0.584(0.307)$. & $0.267(0.333)$ \\
$\tau_{6}$ & $0.617(0.307)^{*}$ & \\
\hline Model fit & & -157.0278 \\
Log-Likelihood: & -151.5723 & 0.08514592 \\
McFadden's R2: & 0.04207369 & 346.0556 \\
AIC: & 335.1446 &
\end{tabular}

Significant codes: ‘***’ 0.001 ; ‘**’ 0.01 ; ‘*’ 0.05 ; ‘’ 0.1

The estimated parameters can reflect the average effect of the independent variables on the happiness and stress level. In this regard, the marginal effects should be taken into account to capture the effects of the independent variables on the predicted probability of each level of happiness and stress. The marginal effects offer a better understanding of the substantive effect sizes. Tables $\mathbf{4}$ and $\mathbf{5}$ present the marginal effects of the independent variables on the simulated probability of each happiness and stress level. The probability of each happiness and stress category is stimulated by an increase of a variable of interest by one unit. Master/Ph.D. students were less likely to be happy and stressed than bachelor students. A similar study showed that individuals with a degree higher than Bachelor were less likely to be happy [14]. Students with a higher allowance were happier and more stressed than those with a lower allowance. Students who were happier were enticed to study for longer, but studying for longer could make them more stressed. Students who were less happy were more likely to play computer/phone games; in other words, students who were happier were probably not likely to play computer/phone games. Similarly, students with a higher stress level were more likely to play computer/phone games. An increase in the duration of spending time online using social media was associated with an increased probability of higher happiness levels and a decreased probability of higher stress levels. An increase in the duration of speaking on the phone for longer increases the probability of lower happiness categories and increases the probability of higher stress categories. This implies that those students who were less happy and more stressed preferred to speak on the phone for longer. Students who were less stressed were less likely to do exercise at home. On the other hand, those who were more stressed were more likely to do exercise for longer, thereby being happier. Students who read the news related to the COVID-19 outbreak for longer were more likely to be stressed because of a sudden increase in confirmed COVID-19 cases during that time in Thailand. This finding is similar to the announcement of the WHO that the 
sudden stream of the COVID-19 news reports could cause anyone to feel worried. The WHO suggests that people seek information from trusted sources to distinguish facts from rumors because facts can minimize fear [1].

Table 4 Marginal effects of the independent variables on the probability of happiness level (standard error).

\begin{tabular}{lccccccc}
\hline Variables & $\mathbf{H L}=\mathbf{1}$ & $\mathbf{H L}=\mathbf{2}$ & $\mathbf{H L}=\mathbf{3}$ & $\mathbf{H L}=\mathbf{4}$ & $\mathbf{H L}=\mathbf{5}$ & $\mathbf{H L}=\mathbf{6}$ & $\mathbf{H L}=\mathbf{7}$ \\
\hline Education & 0.046 & 0.013 & 0.048 & 0.012 & -0.056 & -0.049 & -0.018 \\
& $(0.04)$ & $(0.013)$ & $(0.042)$ & $(0.017)$ & $(0.049)$ & $(0.043)$ & $(0.018)$ \\
Allowance & -0.049 & -0.014 & -0.051 & -0.013 & 0.06 & 0.052 & 0.019 \\
& $(0.04)$ & $(0.013)$ & $(0.042)$ & $(0.017)$ & $(0.049)$ & $(0.042)$ & $(0.018)$ \\
Study & -0.008 & -0.002 & -0.008 & -0.002 & 0.009 & 0.008 & 0.003 \\
& $(0.004)$. & $(0.001)$ & $(0.004)$. & $(0.002)$ & $(0.005)$. & $(0.005)$. & $(0.002)$ \\
Games & 0.005 & 0.001 & 0.005 & 0.001 & -0.006 & -0.005 & -0.002 \\
& $(0.005)$ & $(0.001)$ & $(0.006)$ & $(0.002)$ & $(0.007)$ & $(0.006)$ & $(0.002)$ \\
Social media & -0.002 & -0.001 & -0.002 & -0.001 & 0.002 & 0.002 & 0.001 \\
& $(0.006)$ & $(0.001)$ & $(0.006)$ & $(0.001)$ & $(0.007)$ & $(0.006)$ & $(0.002)$ \\
Phone & 0.049 & 0.014 & 0.051 & 0.013 & -0.059 & -0.052 & -0.019 \\
& $(0.028)$. & $(0.01)$ & $(0.03)$. & $(0.015)$ & $(0.034)$. & $(0.03)$. & $(0.014)$ \\
Exercise & -0.099 & -0.028 & -0.103 & -0.027 & 0.12 & 0.105 & 0.039 \\
\multirow{2}{*}{ COVID-19 } & $(0.045)^{*}$ & $(0.019)$ & $(0.05)^{*}$ & $(0.029)$ & $(0.055)^{*}$ & $(0.049)^{*}$ & $(0.025)$ \\
& 0.004 & 0.001 & 0.004 & 0.001 & -0.005 & -0.004 & -0.001 \\
& $(0.01)$ & $(0.003)$ & $(0.01)$ & $(0.003)$ & $(0.012)$ & $(0.011)$ & $(0.004)$ \\
\hline
\end{tabular}

Table 5 Marginal effects of the independent variables on the probability of stress level (standard error).

\begin{tabular}{lccccccc}
\hline Variables & $\mathbf{S L}=\mathbf{1}$ & $\mathbf{S L}=\mathbf{2}$ & $\mathbf{S L}=\mathbf{3}$ & $\mathbf{S L}=\mathbf{4}$ & $\mathbf{S L}=\mathbf{5}$ & $\mathbf{S L}=\mathbf{6}$ & $\mathbf{S L}=\mathbf{7}$ \\
\hline Education & 0.046 & 0.12 & 0.063 & 0.058 & -0.053 & -0.105 & -0.142 \\
& $(0.026)$. & $(0.051)^{*}$ & $(0.031)^{*}$ & $(0.033)$ & $(0.034)$ & $(0.05)^{*}$ & $(0.059)^{*}$ \\
Allowance & -0.001 & -0.004 & -0.002 & -0.002 & 0.002 & 0.004 & 0.005 \\
& $(0.016)$ & $(0.043)$ & $(0.022)$ & $(0.021)$ & $(0.019)$ & $(0.037)$ & $(0.051)$ \\
Study & 0.001 & 0.003 & 0.001 & 0.001 & -0.001 & -0.002 & -0.003 \\
& $(0.001)$ & $(0.004)$ & $(0.002)$ & $(0.002)$ & $(0.002)$ & $(0.004)$ & $(0.005)$ \\
Games & -0.003 & -0.007 & -0.004 & -0.003 & 0.003 & 0.006 & 0.009 \\
& $(0.002)$ & $(0.006)$ & $(0.003)$ & $(0.003)$ & $(0.003)$ & $(0.006)$ & $(0.008)$ \\
Social media & 0.001 & 0.004 & 0.002 & 0.002 & -0.002 & -0.004 & -0.005 \\
& $(0.002)$ & $(0.006)$ & $(0.003)$ & $(0.003)$ & $(0.003)$ & $(0.006)$ & $(0.008)$ \\
Phone & -0.043 & -0.112 & -0.059 & -0.054 & 0.049 & 0.098 & 0.133 \\
& $(0.022)$ & $(0.039)^{* *}$ & $(0.025)^{*}$ & $(0.027) *$ & $(0.028)$ & $(0.039)^{*}$ & $(0.045)^{* *}$ \\
Exercise & -0.028 & -0.075 & -0.039 & -0.036 & 0.033 & 0.065 & 0.089 \\
& $(0.022)$ & $(0.052)$ & $(0.029)$ & $(0.028)$ & $(0.027)$ & $(0.047)$ & $(0.062)$ \\
COVID-19 & -0.011 & -0.028 & -0.015 & -0.013 & 0.012 & 0.025 & 0.033 \\
& $(0.007)$ & $(0.015)$. & $(0.009)$ & $(0.009)$ & $(0.008)$ & $(0.014)$. & $(0.018)$. \\
\hline
\end{tabular}


According to the findings discussed above, students are suggested to do exercise at home, spend time online using social media, speak on the phone with relatives/friends, watch movies/listen to music, and play computer/phone games to relieve stress and improve life satisfaction. Regarding the empirical findings, universities should persuade foreign students to join at-home activities to improve lifesatisfaction and well-being and provide specific support, specifically high-speed internet access and downloadable e-books and research articles. Similarly, the WHO encourages people to engage in physical activities during the COVID-19 outbreak to take care of their health [1].

\section{Conclusions, limitations, and recommendations}

The study intended to understand the at-home activity involvement and well-being of foreign students in Thailand during the COVID-19 pandemic outbreak. A case study of SIIT-TU, Pathum Thani, with a primary dataset of 42 samples, was taken into account using the ordered probit model. The students studied at home for $6.27 \mathrm{~h}$, watched movies/listened to music for $2.98 \mathrm{~h}$, played computer/phone games for $2.42 \mathrm{~h}$, used social media for $2.80 \mathrm{~h}$, spoke on the phone for $0.79 \mathrm{~h}$, did exercise at home for $0.36 \mathrm{~h}$, and read the news related to the COVID-19 epidemic for $0.94 \mathrm{~h}$ per day on average. This implies that foreign students spent the most time on study and the least time on doing exercise at home. The model estimation results are concluded as follows. Students who were happier and less stressed were more likely to study for longer at home, and students who were less happy and more stressed preferred to speak on the phone for longer. An increase in the duration of using social media increased the probability of higher happiness levels and decreased the probability of higher stress levels. Doing exercise at home for longer increased the likelihood of being happy. Those who were more stressed intended to do exercise for longer, thereby ameliorating higher happiness levels. Students who were happier were less likely to read the news of COVID-19 disease outbreak, or students who read the COVID-19 disease-related news were more stressed. Therefore, students should do exercise at home, spend time online using social media, speak on the phone with relatives/friends, watch movies/listen to music, and play computer/phone games to improve life satisfaction and emotional health. Students should read the news about the COVID-19 disease from trusted sources to distinguish facts from rumors.

Even though this was a novel study of the subjective well-being and at-home activities of foreign college students in Thailand during the class suspension caused by the COVID-19 disease outbreak, there are some inherent limitations, including the small sample size and the case study being conducted at SIITTU only. These limitations were due to the very dynamic and uncertain situation and time and survey tool constraints, viz., the surveyors not being able to reach respondents face-to-face. Additionally, the data collection was on the basis of the self-reporting approach, which cannot avoid a lack of honest, accurate, and bias-free reporting. Future studies are suggested to study the whole of Bangkok and Thailand, with a larger data sample size, and which targets the people groups who are most exposed to the COVID-19 disease (e.g., low-income households, frontline healthcare workers, people with chronic diseases, people with disability, children, people residing in high population density areas, people living in slum or illegal areas, and migrants and refugees).

\section{Acknowledgments}

The authors are very grateful to three anonymous reviewers for their voluntary efforts and expertise to give constructive comments for the earlier draft of the manuscript. Also, the authors would like to thank foreign college students of Sirindhorn International Institute of Technology, Thammasat University, Thailand, who spent their precious time to fill out the survey form. The outcome of the present paper would not have been achieved without their contribution and kind support along the way. 


\section{References}

[1] World Health Organization. Mental Health and Psychosocial Considerations During COVID-19 Outbreak. World Health Organization. Available at: https://www.who.int/docs/defaultsource/coronaviruse/mental-health-considerations.pdf?sfvrsn=6d3578af_2, accessed March 2020.

[2] World Health Organization. Coronavirus disease (COVID-19) Pandemic. Available at: https://www.who.int/emergencies/diseases/novel-coronavirus-2019, accessed April 2020.

[3] CD Rio and PN Malani. COVID-19: New insights on a rapidly changing epidemic carlos. J. Am. Med. Assoc. 2020; 323, 1339-40.

[4] J Liu, J Zhou, J Yao, X Zhang, L Li, X Xu, X He, B Wang, S Fu, T Niu, J Yan, Y Shi, X Ren, J Niu, W Zhu, S Li, B Luo and K Zhang. Impact of meteorological factors on the COVID-19 transmission: A multi-city study in China. Sci. Total Environ. 2020; 726, 138513.

[5] J Hopman and B Allegranzi. Managing COVID-19 in Low- and Middle-Income Countries. J. Am. Med. Assoc. 2020; 323, 1549-550.

[6] KH Kim. COVID-19. Int. Neurourol. J. 2020; 24, 1-1.

[7] World Health Organization. Mental health and psychological resilience during the COVID-19 pandemic. Available at: http://www.euro.who.int/en/health-topics/health-emergencies/coronaviruscovid-19/news/news/2020/3/mental-health-and-psychological-resilience-during-the-covid-19pandemic, accessed April 2020.

[8] World Health Organization. Statement - Physical and mental health key to resilience during COVID-19 pandemic. Available at: http://www.euro.who.int/en/media-centre/sections/statements/ 2020/statement-physical-and-mental-health-key-to-resilience-during-covid-19-pandemic, accessed April 2020.

[9] B Pfefferbaum and CS North. Mental health and the Covid-19 pandemic. N. Engl. J. Med. 2020; 383, 510-2.

[10] T Shanafelt, J Ripp and M Trockel. Understanding and addressing sources of anxiety among health care professionals during the COVID-19 pandemic. J. Am. Med. Assoc. 2020; 323, 2133-4.

[11] HJ McLaren, KR Wong, KN Nguyen and KND Mahamadachchi. Covid-19 and women's triple burden: Vignettes from Sri Lanka, Malaysia, Vietnam and Australia. Soc. Sci. 2020; 9, 5.

[12] J Corburn, D Vlahov, B Mberu, L Riley, WT Caiaffa, SF Rashid, A Ko, S Patel, S Jukur, E Martínez-Herrera, S Jayasinghe, S Agarwal, B Nguendo-Yongsi, J Weru, S Ouma, K Edmundo, T Oni and H Ayad. Slum health: Arresting COVID-19 and improving well-being in urban informal settlements. J. Urban Heal. 2020; 97, 348-57.

[13] Prachatai. Thailand declares a State of Emergency, closes borders, tells senior citizens to stay home. Available at: https://prachatai.com/english/node/8429, accessed April 2020.

[14] H Dong, J Zhang and C Cirillo. Exploring, understanding, and modeling the reciprocal relation between leisure and subjective well-being. Transp. Res. Part A Policy Pract. 2019; 130, 813-24.

[15] RP Rajkumar. COVID-19 and mental health: A review of the existing literature. Asian J. Psychiatr. $2020 ; \mathbf{5 2}, 102066$.

[16] KE Train. Discrete Choice Methods with Simulation. Cambridge University Press, Cambridge, UK, 2003.

[17] DA Hensher, JM Rose and WH Greene. Applied Choice Analysis. Cambridge University Press, Cambridge, UK, 2005.

[18] AS Fullerton and J Xu. Ordered Regression Models. Taylor \& Francis Group, London, UK, 2016.

[19] N Carroll. Oglmx: A Package for Estimation of Ordered Generalized Linear Models. Available at: https://cran.r-project.org/web/packages/oglmx/vignettes/oglmxVignette.pdf, accessed April 2020. 